NBER WORKING PAPER SERIES

\title{
DO DOCTORS PRACTICE DEFENSIVE MEDICINE?
}

Daniel P. Kessler

Mark McClellan

Working Paper 5466

\author{
NATIONAL BUREAU OF ECONOMIC RESEARCH \\ 1050 Massachusetts Avenue \\ Cambridge, MA 02138 \\ February 1996
}

We would like to thank Randall Bovbjerg, David Genesove, Jerry Hausman, Paul Joskow, Lawrence Katz, W. Page Keeton, Gary King, A. Mitchell Polinsky, George Shepherd, Frank Sloan, seminar participants at Michigan, Northwestern, and NBER, and two anonymous referees for advice, assistance, and helpful comments. Jeffrey Geppert and Mohan Ramanujan provided excellent research assistance. Funding from the Harvard/MIT Research Training Group in Positive Political Economy, the John M. Olin Foundation, and the National Institute on Aging is greatly appreciated. All errors are our own. This paper is part of NBER's research programs in Law and Economics, and Health Care. Any opinions expressed are those of the authors and not those of the National Bureau of Economic Research.

(ㄷ 1996 by Daniel P. Kessler and Mark McClellan. All rights reserved. Short sections of text, not to exceed two paragraphs, may be quoted without explicit permission provided that full credit, including $\odot$ notice, is given to the source. 


\title{
DO DOCTORS PRACTICE DEFENSIVE MEDICINE?
}

\begin{abstract}
"Defensive medicine" is a potentially serious social problem: if fear of liability drives health care providers to administer treatments that do not have worthwhile medical benefits, then the current liability system may generate inefficiencies many times greater than the costs of compensating malpractice claimants. To obtain direct empirical evidence on this question, we analyze the effects of malpractice liability reforms using data on all elderly Medicare beneficiaries treated for serious heart disease in 1984,1987 , and 1990 . We find that malpractice reforms that directly reduce provider liability pressure lead to reductions of 5 to 9 percent in medical expenditures without substantial effects on mortality or medical complications. We conclude that liability reforms can reduce defensive medical practices.
\end{abstract}

Daniel P. Kessler

Graduate School of Business

Stanford University

Stanford, CA 94305

and NBER
Mark McClellan

Department of Economics

Stanford University

Stanford, CA 94305

and NBER 


\section{Introduction}

The medical malpractice liability system has two principal roles: providing redress to individuals who suffer negligent injuries, and creating incentives for doctors to provide appropriately careful treatment to their patients [Bell 1984]. Malpractice law seeks to accomplish these goals by penalizing physicians whose negligence causes an adverse patient health outcome, and using these penalties to compensate the injured patients [Danzon 1985]. However, considerable evidence indicates that the current malpractice system is neither sensitive nor specific in providing compensation. For example, the Harvard Medical Practice Study [1990] found that sixteen times as many patients suffered an injury from negligent medical care as received compensation in New York State in 1984. And, in any event, the cost of compensating malpractice claimants is not an important source of medical expenditure growth: compensation paid and the costs of administering that compensation through the legal system account for less than one percent of expenditures [OTA 1993].

The effects of the malpractice system on physician behavior, in contrast, may have much more substantial effects on health care costs and outcomes, even though virtually all physicians are fully insured against the financial costs of malpractice such as damages and legal defense expenses. Physicians may employ costly precautionary treatments in order to avoid nonfinancial penalties such as fear of reputational harm, decreased self-esteem from adverse publicity, and the time and unpleasantness of defending a claim [Charles, Pyskoty, and Nelson 1988; Weiler et al. 1993].

On one hand, these penalties for malpractice may deter doctors and other providers from putting patients at excessive risk of adverse health outcomes. On the other hand, these penalties 
may also drive physicians to be too careful -- to administer precautionary treatments with minimal expected medical benefit out of fear of legal liability -- and thus to practice "defensive medicine." Many physicians and policymakers have argued that the incentive costs of the malpractice system, due to extra tests and procedures ordered in response to the perceived threat of a medical malpractice claim, may account for a substantial portion of the explosive growth in health care costs [Reynolds, Rizzo, and Gonzalez 1987; OTA 1993, 1994]. The practice of defensive medicine may even have adverse effects on patient health outcomes, if liability induces providers either to administer harmful treatments or forego risky but beneficial ones. For these reasons, defensive medicine is a crucial policy concern [Sloan, Mergenhagen, and Bovbjerg 1991].

Despite this policy importance, there is virtually no direct evidence on the existence and magnitude of defensive medical practices. Such evidence is essential for determining appropriate tort liability policy. In this paper, we seek to provide such direct evidence on the prevalence of defensive medicine by examining the link between medical malpractice tort law, treatment intensity, and patient outcomes. We use longitudinal data on all elderly Medicare recipients hospitalized for treatment of a new heart attack (acute myocardial infarction, or AMI) or of new ischemic heart disease (IHD) in 1984, 1987, and 1990, matched with information on tort laws from the state in which the patient was treated. We study the effect of tort law reforms on total hospital expenditures on the patient in the year after AMI to measure intensity of treatment. We also model the effect of tort law reforms on important patient outcomes. We estimate the effect of reforms on a serious adverse outcome that is common in our study population: mortality within one year of occurrence of the cardiac illness. We also estimate the 
effect of tort reforms on two other common adverse outcomes related to a patient's quality of life: whether the patient experienced a subsequent AMI or other cardiac illness requiring hospitalization in the year following the initial illness.

To the extent that reductions in medical malpractice tort liability are associated with decreases in intensity but not with increases in adverse health outcomes, medical care for these health problems is defensive -- that is, doctors supply a socially excessive level of care due to malpractice liability pressures. Put another way, tort reforms that reduce liability also reduce inefficiency in the medical care delivery system to the extent that they reduce health expenditures that do not provide commensurate benefits. We assess the magnitude of defensive treatment behavior by calculating the cost of an additional year of life or an additional year of cardiac health achieved through treatment intensity induced by specific aspects of the liability system. If liability-induced precaution results in low expenditures per life saved relative to generally accepted costs per life of other medical treatments, then the existing liability system provides incentives for efficient care; but if liability-induced precaution results in high expenditures per life saved, then the liability system provides incentives for socially excessive care. Because the precision with which we measure the consequences of reforms is critical, we include all U.S. elderly patients with heart diseases in 1984, 1987, and 1990 in our analysis.

The first section of the paper discusses the theoretical ambiguity of the impact of the current liability system on efficiency in health care. For this reason, liability policy should be guided by empirical evidence on its consequences for "due care" in medical practice. The second section reviews the previous empirical literature. Though the existing evidence on the effectiveness of alternative liability rules has provided considerable insights, direct evidence on 
the crucial effects of the tort system on physician behavior is virtually nonexistent. The third section presents our econometric models of the effects of liability rules on treatment decisions, costs, and patient outcomes, and formally describes the test for defensive medicine used in the paper. We identify liability effects by comparing trends in treatment choice, costs, and outcomes in states adopting various liability reforms to trends in those that did not; we also review a number of approaches to enriching the model, assisting in the evaluation of its statistical validity and providing further insights into the tort reform effects. The fourth section discusses the details of our data, and motivates our analysis of elderly Medicare beneficiaries for purposes of assessing the costs of defensive medicine. The fifth section presents the empirical results. The sixth section discusses implications for policy, and the last section concludes.

\section{Malpractice Liability and Efficient Precaution In Health Care}

In general, malpractice claims are adjudicated in state courts according to state laws.

These laws require three elements for a successful claim. First, the claimant must show that the patient actually suffered an adverse event. Second, a successful malpractice claimant must establish that the provider caused the event: the claimant must attribute the injury to the action or inaction of the provider, as opposed to nature. Third, a successful claimant must show that the provider was negligent. Stated simply, this entails showing that the provider took less care than that which is customarily practiced by the average member of profession in good standing, given the circumstances of the doctor and the patient [Keeton et al. 1984]. Collectively, this three-part test of the validity of a malpractice claim is known as the "negligence rule."

In addition to patient compensation, the principal role of the liability system is to induce 
doctors to take the optimal level of precaution against patient injury. However, a negligence rule may lead doctors to take socially insufficient precaution, such that the marginal social benefit of precaution would be greater than the marginal social cost; or, it may lead doctors to take socially excessive precaution -- that is, to practice defensive medicine -- such that the marginal social benefit of precaution would be less than the marginal social cost [Farber and White 1991]. The negligence rule may not generate socially optimal behavior in health care because the private incentives for precaution facing doctors and patients differ from the social incentives. First, the costs of accidents borne by the physician differ from the social costs of accidents. Because malpractice insurance is not strongly experience rated [Sloan 1990], physicians bear little of the costs of patient injuries from malpractice; however, physicians bear significant uninsured expenses in response to a malpractice claim, such as the value of time and emotional energy spent on legal defense [OTA 1993: 7]. Second, patients and physicians bear little of the costs of medical care associated with physician precaution in any particular case because most health care is financed through health insurance and because physicians may not be perfect agents for the managers of the organizations in which they practice [McClellan 1995]. Generally, insured expenses for drugs, diagnostic tests, and other services performed for precautionary purposes are much larger than the uninsured cost of the physician's own effort. Third, physicians only bear substantial costs of accidents when patients file claims, and patients may not file a malpractice claim in response to every negligent medical injury [Harvard Medical Practice Study 1990].

The direction and extent of the divergence between the privately and socially optimal levels of precaution depends in part on states' legal environments. Although the basic framework of the negligence rule applies to most medical malpractice claims in the United 
States, individual states have modified their tort law to either expand or limit malpractice liability along various dimensions over the past 30 years. For example, several states have imposed caps on malpractice damages such that recoverable losses are limited to a fixed dollar amount, such as $\$ 250,000$. These modifications to the basic negligence rule can affect both the costs to physicians and the benefits to patients from a given malpractice claim or lawsuit, and thereby also affect the frequency and average settlement amount ("severity") of claims. We use the term malpractice pressure to describe the extent to which a state's legal environment provides high benefits to plaintiffs and/or high costs to physicians (Malpractice pressure can be multidimensional.)

If the legal environment creates little malpractice pressure and externalized costs of medical treatment are small, then the privately optimal care choice may be below the social optimum. In this case, low benefits from filing malpractice claims and lawsuits reduce nonpecuniary costs of accidents for physicians, who may then take less care than the low cost of diagnostic tests, for example, would warrant. However, if the legal environment creates substantial malpractice pressure and externalized costs of treatment are large, then the privately optimal care choice may be above the social optimum: privately chosen care decisions will be defensive. For example, increasing technological intensity (with a reduced share of physician effort costs relative to total medical care costs) and increasing generosity of tort compensation of medical injury would lead to relatively more defensive medical practice.

Incentives to practice defensively may be intensified if judges and juries impose liability with error. For example, the fact that health care providers' precautionary behavior may be ex post difficult to verify may give them the incentive to take too much care [Cooter and Ulen 
1986, Craswell and Calfee 1986]. Excessive care results from the all-or-nothing nature of the liability decision: small increases in precaution above the optimal level may result in large decreases in expected liability.

Because privately optimal behavior under the basic negligence rule may result in medical treatment that has marginal social benefits either greater or less than the marginal social costs, the level of malpractice pressure that provides appropriate incentives is an empirical question. In theory, marginal changes to the negligence rule can either improve or reduce efficiency, depending on their effects on precautionary behavior, total health care costs, and adverse health outcomes. Previous studies have analyzed effects of legal reforms on measures of malpractice pressure, such as the level of compensation paid malpractice claimants. To address the potentially much larger behavioral consequences of malpractice pressure, we study the impact of changes in the legal environment on health care expenditures to measure the marginal social cost of treatment induced by the liability system, and the impact of law changes on adverse health events to measure the marginal social benefit of law-induced treatment. As a result, we can provide direct evidence on the efficiency of a baseline malpractice system and, if it is inefficient, identify efficiency-improving reforms.

\section{Previous Empirical Literature}

The previous empirical literature is consistent with the hypothesis that providers practice defensive medicine, although it does not provide direct evidence on the existence or magnitude of the problem. One arm of the literature uses surveys of physicians to assess whether doctors practice defensive medicine [Reynolds, Rizzo, and Gonzalez 1987; Moser and Musaccio 1991; 
OTA 1994]. Such physician surveys measure the cost of defensive medicine only with further untestable assumptions about the relationship between survey responses, actual treatment behavior, and patient outcomes. Although surveys indicate that doctors believe that they practice defensively, surveys only provide information about what treatments doctors say that they would administer in a hypothetical situation; they do not measure behavior in real situations.

Another body of work uses clinical studies of the effectiveness of intensive treatment [Leveno et al. 1986; Shy et al. 1990]. These studies find that certain intensive treatments which are generally thought to be used defensively have an insignificant impact on health outcomes. Similarly, clinical evaluations of malpractice control policies at specific hospitals have found that intensive treatments thought to serve a defensive purpose are "overused" by physicians [Masters et al. 1987]. However, this work does not directly answer the policy question of interest: does intensive treatment administered out of fear of malpractice claims have any effect on patient outcomes? Few medical technologies in general use have been shown to be ineffective in all applications, and the average effect of a procedure in a population may be quite different from its effect at the margin, for example in the additional patients who receive it because of more stringent liability rules [McClellan 1995]. Evaluating malpractice liability reforms requires evidence on the effectiveness of intensive treatment in the "marginal" patients.

A third, well-developed arm of the literature estimates the effects of changes in the legal environment on measures of the compensation paid and the frequency of malpractice claims. Danzon $[1982,1986]$ and Sloan, Mergenhagen, and Bovbjerg [1989] find that tort reforms that cap physicians' liability at some maximum level or require awards in malpractice cases to be 
offset by the amount of compensation received by patients from collateral sources ${ }^{1}$ reduce payments per claim. ${ }^{2}$ Danzon [1986] also finds that collateral-source-rule reforms and statuteof-limitations reductions reduce claim frequency. Based on data from malpractice insurance markets, Zuckerman, Bovbjerg, and Sloan [1990] and Barker [1992] find similar results: Zuckerman, Bovbjerg, and Sloan find that caps on damages and statute-of-limitations reductions reduce malpractice premiums, and Barker finds that caps on damages increase profitability. Despite significant variety in data and methods, this literature contains an important unified message about the types of legal reforms that affect physicians' incentives. The two reforms most commonly found to reduce payments to and the frequency of claims, caps on damages and collateral source rule reforms, share a common property: they directly reduce expected malpractice awards. Caps on damages truncate the distribution of awards; mandatory collateral source offsets shift down its mean. Other malpractice reforms that only affect malpractice awards indirectly, such as reforms imposing mandatory periodic payments (which require damages in certain cases to be disbursed in the form of annuity that pays out over time) or statute-of-limitations reductions, have had a less discernable impact on liability and hence on malpractice pressure.

However, estimates of the impact of reforms on frequency and severity from these analyses are only the first step toward answering the policy question of interest: do doctors practice defensive medicine? Taken alone, they only provide evidence of the effects of legal reforms on doctors' incentives; they do not provide evidence of the effects of legal reforms on doctors' behavior. Identifying the existence of defensive treatment practices and the extent of inefficient precaution due to legal liability requires a comparison of the response of costs of 
precaution and the response of losses from adverse events to changes in the legal environment. A number of studies have sought to investigate physicians' behavioral response to malpractice pressure. These studies generally have analyzed the costs of defensive medicine by relating physicians' actual exposure to malpractice claims to clinical practices and patient outcomes [Rock 1988; Harvard Medical Practice Study 1990; Localio et al. 1993; Baldwin et al. 1995]. Rock, Localio et al., and the Harvard Medical Practice Study find results consistent with defensive medicine; Baldwin et al. do not. However, concerns about unobserved heterogeneity across providers and across small geographic areas qualify the results of all of these studies. The studies used frequency of claims or magnitude of insurance premiums at the level of individual doctors, hospitals, or areas within a single state over a limited time period to measure malpractice pressure. Because malpractice laws within a state at a given time are constant, the measures of malpractice pressure used in these studies arose not from laws but from primarily unobserved factors at the level of individual providers or small areas, creating a potentially serious problem of selection bias. For example, the claims frequency or insurance premiums of a particular provider or area may be relatively high because the provider is relatively low quality, because the patients are particularly sick (and hence prone to adverse outcomes), because the patients had more "taste" for medical interventions (and hence more likely to disagree with their provider about management decisions), or because of many other factors; the sources of the variation in legal environment are unclear and probably multifactorial. All of these factors are extremely difficult to capture fully in observational datasets, and could lead to an apparent but noncausal association between measured malpractice pressure and treatment decisions or outcomes. 
Thus, while previous analyses have provided a range of insights about the malpractice liability system, they have not provided direct empirical evidence on how malpractice reforms would actually affect physician behavior, medical costs, and health outcomes.

\section{Econometric Models}

Our statistical methods seek to measure the effects of changes in an identifiable source of variation in malpractice pressure influencing medical decision making -- state tort laws -- that is not related to unobserved heterogeneity across patients and providers. We compare time trends across reforming and nonreforming states during a seven-year period in inpatient hospital expenditures, and in outcome measures including all-cause cardiac mortality as well as the occurrence of cardiac complications directly related to quality of life. We model average expenditures and outcomes as essentially nonparametric functions of patient demographic characteristics, state legal and political characteristics, and state- and time-fixed-effects. We model the effects of state tort law changes as differences in time trends before and after the tort law changes. We test for the existence and magnitude of defensive medicine based on the relationship of the law-change effects on medical expenditures and health outcomes.

While this strategy fundamentally involves differences-in-differences between reforming and nonreforming states to identify effects, we modify conventional differences-in-differences estimation strategies in several ways. First, as noted above, our models include no potentially restrictive parametric or distributional assumptions about functional forms for expenditures or health outcomes. Second, we do not model reforms as simple one-time shifts. Malpractice reforms might have more complex, longer-term effects on medical practices for a number of 
reasons. Law changes may not have instantaneous effects because it may take time for lawyers, physicians, and patients to learn about their consequences for liability, and then to reestablish equilibrium practices. Law changes may affect not only the static climate of medical decision making, but also the climate for further medical interventions by reducing pressure for technological intensity growth. Thus, the long-term consequences of reforms may be different from their short-term effects. By using a panel dataset including a seven-year panel, our modeling framework permits a more robust analysis of differences in time trends before and after adoption.

We use a panel-data framework with observations on successive cohorts of heart disease patients for estimating the prevalence of defensive medicine. In state $\mathrm{s}=1$...S during year $\mathrm{t}=$ $1 \ldots \mathrm{T}$, our observational units consist of individuals $\mathrm{I}=1 \ldots \mathrm{N}_{\mathrm{st}}$ who are hospitalized with new occurrences of particular illnesses such as a heart attack. Each patient has observable characteristics $\mathrm{X}_{\mathrm{ist}}$, which we describe as a fully-interacted set of binary variables, as well as many unobservable characteristics that also influence both treatment decisions and outcomes. The individual receives treatment of aggregate intensity $\mathbf{R}_{\text {ist }}$, where $\mathbf{R}$ denotes total hospital expenditures in the year after the health event. The patient has a health outcome $\mathrm{O}_{\text {ist }}$, possibly affected by the intensity of treatment received, where a higher value denotes a more adverse outcome ( $\mathrm{O}$ is binary in our models).

We define state tort systems in effect at the time of each individual's health event based on the existence of two categories of reforms from a maximum-liability regime: direct and indirect malpractice reforms. Previous studies, summarized in Section II, found differences between these types of reforms on claims behavior and malpractice insurance premiums (Section 
IV below discusses our reform classification in detail). We denote the existence of direct reforms in state $s$ at time $t$ using two binary variables $L_{m s t}: L_{1 s t}=1$ if state $s$ has adopted a direct reform at time $t$, and $L_{2 s t}=1$ if state $s$ has adopted an indirect reform at time $t$.

We first estimate linear models of average expenditure and outcome effects using these individual-level variables. The expenditure models are of the form

$$
R_{i s t}=\theta_{t}+\alpha_{s}+X_{i s t} \beta+W_{s t} \gamma+L_{s t} \phi_{m}+v_{i s t} \text {, }
$$

where $\theta_{t}$ is a time fixed-effect, $\alpha_{s}$ is a state fixed-effect, $X_{\text {ist }}$ is a fully-interacted vector of binary variables describing observable individual characteristics, $\mathrm{W}_{\mathrm{st}}$ is a vector of variables describing the legal-political environment of the state over time, $\beta$ and $\gamma$ are vectors of the corresponding average-effect estimates for the demographic controls and additional state-time controls, $\mathrm{L}_{\mathbf{s t}}$ is a two-dimensional binary vector describing the existence of malpractice reforms, $\phi_{\mathrm{m}}$ is the twodimensional average effect of malpractice reforms on growth rate, and $v_{i s t}$ is a mean-zero independently-distributed error term with $E\left(v_{\text {ist }} \mid X_{\text {ist }} L_{s t}\right)=0$. Because legal reforms may affect both the level and the growth rate of expenditures, we estimate different baseline time trends $\theta_{t}$ for states adopting reforms before 1985 (which were generally adopted before 1980) and nonadopting states. Our dataset includes essentially all elderly patients hospitalized with the heart diseases of interest for the years of our study, so that our results describe the actual average differences in trends associated with malpractice reforms in the U.S. elderly population. We report standard errors for inferences about average differences that might arise in potential populations (e.g., elderly patients with these health problems in other years). Our model assumes that patients grouped at the level of state and time have similar distributions of 
unobservable characteristics that influence medical treatments and health outcomes. Assuming that malpractice laws affect malpractice pressure, but does not directly affect patient expenditures or outcomes, then the coefficients $\phi$ identify the average effects of changes in malpractice pressure resulting from malpractice reforms.

To distinguish short-term and long-term effects of legal reforms, we estimated less restrictive models of the average effects of legal reforms that utilize the long duration of our panel. These "dynamic" models estimate separate growth rate effects $\phi_{\mathrm{md}}$ based on time-sinceadoption:

$$
R_{i s t}=\theta_{t}+\alpha_{s}+X_{i s t} \beta+W_{s t} \gamma+L_{s t} d_{s t} \phi_{m d}+v_{i s t}
$$

where we include separate short-term average effects $\phi_{\mathrm{m} 0}$ and long-term average effects $\phi_{\mathrm{ml}}$. We estimate the short-term effect of the law (within two years of adoption) $\phi_{\mathrm{mo}}$ by setting $d_{\mathrm{st0}}=1$ for 1985-87 adopters in 1987 and 1988-90 adopters in 1990, and we estimate the long-term effect (three to five years since adoption) $\phi_{\mathrm{ml}}$ by setting $d_{\mathrm{st} 1}=1$ for 1985-87 adopters in 1990 .

The estimated average effects $\phi_{\mathrm{md}}$ in these models form the basis for tests of the effects of malpractice reforms on health care expenditures and outcomes, and thus for tests of the existence and magnitude of defensive medicine. In all of these models, there is strong evidence of defensive medicine if, for direct or indirect reforms $\mathrm{m}, \phi_{\mathrm{md}}<0$ in our models of medical expenditures and $\phi_{\mathrm{md}}=0$ in our models of health outcomes. In other words, if a state law reform is associated with a reduction in the growth rate of intensive treatment use and does not adversely affect the growth rate of adverse health outcomes through its impact on treatment decisions, then malpractice pressure is too high from the perspective of social welfare and 
defensive medicine exists. More generally, defensive medicine exists if the effect of malpractice reforms on expenditures is "large" relative to the effect on health outcomes. Thus, in the results that follow, we test both whether expenditure and outcome effects of reforms differ substantially from zero, as well as the ratio of expenditure to outcome effects.

The power of the test for defensive medicine depends on the statistical precision of the estimated effects of law reforms on outcomes; consequently, we evaluate the confidence intervals surrounding our estimates of outcome effects carefully. ${ }^{3}$ It is not feasible to collect information on all health outcomes that may matter to some degree to individual patients. Instead, our tests focus on important health outcomes, including mortality and significant cardiac complications, which are reliably observed in our study population. Because the cardiac complications we consider reflect the two principal ways in which poorly-treated heart disease would affect quality of life (e.g., through further chest pain symptoms or through impaired cardiac function), estimates of effects on these health outcomes along with mortality would presumably capture any substantial health consequences of malpractice reforms.

We estimated additional specifications of our models to test whether reform adoption is not in fact correlated with unobserved trends in malpractice pressures or patient characteristics across the state-time groups. One set of specification tests was based on the inclusion of random effects for state-time interactions or the use of Huber-White standard error corrections to account for any important error correlations arising after accounting for state and time effects, i.e., within state-time cells. ${ }^{4}$

Another set of specification tests involved evaluating a range of variables $\mathrm{W}_{\mathrm{st}}$ summarizing the political and regulatory environment in each state at each point in time, to test 
whether various factors that might influence reform adoption influence our estimates of reform effects on either expenditure or health outcomes. Since the main cause of the tort reforms that are the focus of our study was nationwide crisis in all lines of commercial casualty insurance, it is unlikely that endogeneity of reforms is a serious problem [Priest 1987; Rabin 1988]. However, Campbell, Kessler, and Shepherd [1996] show that the concentration of physicians and lawyers in a state and measures of states' political environment are correlated with liability reforms, and Danzon [1982] shows that the concentration of lawyers in a state are correlated with both the compensation paid to malpractice claims and the enactment of reforms. ${ }^{5}$ Consequently, we control for the political party of each state's governor, the majority political party of each house of each state's legislature, and lawyers per capita in all of the regressions. ${ }^{6}$

A third set of specification tests relied on other tort reforms enacted in the 1980s which would not be expected to have much impact on malpractice liability cases in the elderly during the time frame of our study. However, these reforms might be correlated with relevant malpractice reforms, for example if general concerns about liability pressures in all industries led to broad legal reforms. If such reforms were correlated with included reforms, then our estimates might overstate the impact of the malpractice law reforms that we analyze.

Although results from the malpractice-claim studies discussed above suggest that these omitted reforms are unimportant relative to reforms with a more direct effect on awards, we investigate the validity of our assumption of no omitted variable bias by estimating the impact of reforms to states' statutes of limitations. Statutes of limitations are most relevant in situations involving latent injuries; malpractice arising out of AMI in the elderly would involve an injury the adverse consequences of which would appear before any statute of limitations would exclude 
an injured patient. Nonetheless, statutes of limitations are the potentially most important reform not included in our study (23 states shortened their statutes of limitations between 1985 and 1990, and Danzon [1986] found shorter statutes of limitations to reduce claims frequency). If our models are correctly specified, then statute of limitations reforms should have no effect on the treatment intensity and outcome decisions that we analyze; if omitted variable bias is a problem, however, statute of limitations reforms may show a significant estimated effect.

Finally, because all of our specifications control for fixed differences across states, they do not allow us to estimate differences in the baseline levels of intensive treatment and adverse health outcomes. Thus, we also estimate additional versions of all of our models with region effects only, to explore baseline differences in treatment rates, costs, and outcomes across legal regimes.

\section{Data}

The data used in our analysis come from two principal sources. ${ }^{7}$ Our information on the characteristics, expenditures, and outcomes for elderly Medicare beneficiaries with heart disease are derived from comprehensive longitudinal claims data for the vast majority of elderly Medicare beneficiaries who were admitted to a hospital with a new primary diagnosis (no admission with a either health problem in the preceding year) of either acute myocardial infarction (AMI) or ischemic heart disease (IHD) in 1984, 1987, and 1990. Data on patient demographic characteristics were obtained from the Health Care Financing Administration HISKEW enrollment files, with death dates based on death reports validated by the Social Security Administration. Measures of total one-year hospital expenditures were obtained by 
adding up all reimbursement to acute-care hospitals (including copayments and deductibles not paid by Medicare) from insurance claims for all hospitalizations in the year following each patient's initial admission for AMI or IHD. Measures of the occurrence of cardiac complications were obtained by abstracting data on the principal diagnosis for all subsequent admissions (not counting transfers) in the year following the patient's initial admission. Cardiac complications included rehospitalizations within one year of the initial event with a primary diagnosis (principal cause of hospitalization) of either subsequent AMI or heart failure. Treatment of IHD and AMI patients is intended to prevent subsequent AMIs if possible, and the occurrence of heart failure requiring hospitalization is evidence that the damage to the patient's heart from ischemic disease has serious functional consequences. The programming rules used in the data set creation process and sample exclusion criteria were virtually identical to those reported in McClellan and Newhouse [1995a, 1995b].

We analyze cardiac disease patients because the choice of a particular set of diagnoses permits detailed exploration of the health and treatment consequences of policy reforms. Cardiac disease and its complications are the leading cause of medical expenditures and mortality in the United States. A majority of AMIs and IHD hospitalizations occur in the elderly, and both mortality and subsequent cardiac complications are relatively common occurrences in this population. Thus, this condition provides both a relatively homogeneous set of patients and outcomes (to analyze the presence of defensive medicine with reasonable clinical detail), and medical expenditures are large enough and the relevant adverse outcomes common enough that the test for defensive medicine can be a precise one. Furthermore, because AMI is essentially a more severe form of the same underlying illness as is IHD, we can assess whether 
reforms affect more or less severe cases of a health problem differently by comparing AMI to IHD patients.

In addition, cardiovascular illness is likely to be sensitive to defensive medical practices. In a ranking of illnesses by the frequency of and payments to the malpractice claims that they generate, AMI is the third-most prevalent and costly, behind only malignant breast cancer and brain-damaged infants [PIAA 1993]. AMI is also distinctive because of the severity of medical injury associated with malpractice claims: conditional on a claim, patients with AMI suffer injury that rates 8.2 on the National Association of Insurance Commissioners nine-point severity scale, the second-highest severity rating of any malpractice-claim-generating health problem [PIAA 1993]. Cardiovascular illnesses and associated procedures also include 7 of the 40 most prevalent and costly malpractice-claim-generating health problems [PIAA 1993].

We focus on elderly patients in part because no comparable longitudinal microdata exists for nonelderly U.S. patient populations. However, there are other advantages to concentrating on this population. Several studies have documented that claims rates are lower in the elderly than in the nonelderly population, presumably because losses from severe injuries would be smaller given the patients' shorter expected survival [Weiler et al. 1993]. This hypothesis suggests that physicians are least likely to practice defensively for elderly patients; thus, treatment decisions and expenditures in this population would be the least sensitive to legal reforms. Similarly, relatively low baseline incentives for defensive practices and the relatively high frequency of adverse outcomes in the elderly implies that this population can provide the most sensitive tests for adverse health effects of reforms. These considerations suggest that analysis of elderly patients provides a lower bound on the costs of defensive medicine. In any 
event, trends in practice patterns over time have been similar for elderly and nonelderly patients (e.g., intensity of treatment have increased dramatically and survival rates have improved for both groups, National Center for Health Statistics [1994]); thus, we would expect the findings for this population to be qualitatively similar to results for the nonelderly, were such a longitudinal empirical analysis possible.

Table 1 describes the elderly population with AMI and IHD from the years of our study. Between 1984 and 1990, the elderly AMI population aged slightly and the share of males in the IHD population increased slightly, but the characteristics of AMI and IHD patients were otherwise relatively stable. The number of AMI patients in an annual cohort declined slightly (from 233,000 to 221,000 ) while the number of IHD patients increased (from 357,000 to 423,000). Changes in real hospital expenditures in the year following the AMI or IHD event were dramatic, for example, one-year average hospital expenditures for AMI patients rose from $\$ 10,880$ in 1984 to $\$ 13,140$ in 1990 (in constant 1991 dollars), a real growth rate of around 4 percent per year. These expenditure trends are primarily attributable to changes in intensity; because of Medicare's "prospective" hospital payment system, reimbursement given treatment choice for Medicare patients actually declined during this period. This growth in expenditures and treatment intensity was associated with significant mortality reductions, from 39.9 percent to 35.3 percent for AMI patients (with the bulk of the reduction coming after 1987) and from 13.5 percent to 10.8 percent for IHD patients (with the bulk coming before 1987). However, the AMI survival improvements -- but not the IHD improvements -- were associated with corresponding increases in recurrent AMIs and in heart failure complications. This underscores that the role of changes in intensity versus other factors -- as well as any role of changes in liability -- in all of 
these trends is difficult to identify directly.

Second, building on prior efforts to collect information on state malpractice laws (e.g., Sloan, Mergenhagen, and Bovbjerg [1989]), we have compiled a comprehensive database on reforms to state liability laws and state malpractice-control policies that contain information on several types of legal reforms from 1969 to $1992 .^{8}$ The legal regime indicator variables are defined such that the level of liability imposed on defendants in the baseline is at a hypothetical maximum. ${ }^{9}$

Eight characteristics of state malpractice law, representing divergences from the baseline legal regime, are summarized in Table $2 \mathrm{~A}$. We divide these eight reforms into two groups of four reforms each: reforms that directly reduce malpractice awards and reforms that only reduce awards indirectly. "Direct" reforms include reforms that truncate the upper tail of the distribution of awards, such as caps on damages and the abolition of punitive damages, and reforms that shift down the mean of the distribution, such as collateral-source rule reform and abolition of mandatory prejudgment interest. "Indirect" reforms include other reforms that have been hypothesized to reduce malpractice pressure but only affect awards indirectly, for instance through restricting the range of contracts that can be enforced between plaintiffs and contingency-fee attorneys. As discussed in Section $I$ above, we chose this division because the previous empirical literature generally found the impact of direct reforms to be larger than the impact of indirect reforms on physicians' incentives through their effect on the compensation paid and the frequency of malpractice claims. Each of the observations in the Medicare data set was matched with a set of two tort law variables that indicated the presence or absence of direct or indirect malpractice reforms at the time of their initial hospitalization. 
Table 2B contains the effective dates for the adoption of direct and indirect reforms for each of the 50 states. The table shows that a number of states have implemented legal reforms at different times. For example, 13 states never adopted any direct reforms, 23 states adopted direct reforms between 1985 and 1990, and 18 states adopted direct reforms 1984 or earlier (adoptions plus nonadoptions exceed 50 because some states adopted both before and after 1985). Similarly, 16 states never adopted any indirect reforms, 22 states adopted indirect reforms between 1985 and 1990, and 18 states adopted indirect reforms 1984 or earlier. Adoption of direct and indirect reforms is not strongly related; 16 states that never adopted reforms of one type have adopted reforms of the other.

\section{V.Empirical Results}

Table 3 previews our basic difference-in-difference (DD) analysis by reporting unadjusted conditional means for expenditures and mortality for four patient groups, based on the timing of malpractice reforms. Expenditure levels in 1984 (our base year) were slightly higher in states passing reforms between 1985-87 and lower in states passing reforms between 1988-90. Baseline mortality rates were slightly lower for AMI and higher for IHD in the 198587 reform states, and conversely for the $1988-90$ reform states. Thus, overall, reform states looked very similar to nonreform states in terms of baseline expenditures and outcomes. States with earlier reforms (pre-1985) had slightly higher base year expenditures but similar base year mortality rates. The table shows that expenditure growth in reform states was smaller than in nonreform states during the study years; altogether, growth was two to six percent slower in the reform compared to the nonreform states for AMI, and trend differences were slightly greater for 
IHD. Though mortality trends differed somewhat across the state groups, mortality trends on average were quite similar for reform and nonreform states. These simple comparisons do not account for any differences in trends in patient characteristics across the state groups, do not account for any effects of other correlated reforms, and do not readily permit analysis of dynamic malpractice reform effects. Nonetheless, they anticipate the principal estimation results that follow.

Table 4 presents estimates of a standard DD specification of the effects of tort reforms between 1985 and 1990 on average expenditures and outcomes for AMI; that is, no dynamic reform effects are included. In this and subsequent models, we include fully-interacted demographic effects -- for patient age $(65-69,70-74,75-79,80-89,90-99)$, gender, black or nonblack race, and urban or rural residence -- and controls for contemporaneous political and regulatory changes described previously. For each of the four outcomes -- one-year hospital expenditures, mortality, and AMI and CHF readmissions -- two sets of models are reported. The first set includes complete state and year fixed effects. The second set, intended to illustrate the average differences of states that had adopted reforms before our study began as well as the sensitivity of the results to a more complete fixed-effect specification, includes only time and region effects. As described in Section II, both specifications are linear, the dependent variable in the expenditure models is logged, all coefficient estimates are multiplied by 100 and so can be interpreted as average effects in percent (for expenditure models) or percentage points (for outcomes models), and the standard errors are corrected for heteroskedasticity and grouping at the state/zip-code level.

The estimates of average expenditure growth rates in both specifications are substantial, 
showing an increase in real expenditures of over 21 percent between 1984 and 1990. The estimated DD effects show that expenditures declined by 5.3 percent relative to nonreform states in states that adopted direct reforms. The corresponding DD estimate of the effect of indirect reforms, 1.8 percent, is positive but small; these reforms do not appear to have a substantial effect on expenditures. In the region-effect models, the estimated DD reform effects are slightly larger but qualitatively similar. States that adopted reforms prior to our study period had 19841990 growth rates in expenditures that were slightly larger, by around 3 percent. The regioneffect model shows that these states as a group also had slightly higher expenditure levels in 1984. Because these states generally adopted reforms at least five years before our panel began, our results suggest that direct reforms do not result in relatively slower expenditure growth more than five years after adoption. However, lack of a pre-adoption baseline for and adoption-time heterogeneity among the early-adopting states, as well as the sensitivity of the earlyadopter/nonadopter differential growth rates to alternative specifications (as discussed below), makes interpreting estimates of differential early-adopter/nonadopter growth rates as a long-term effect problematic. And, in any event, in no case would the differential 1984-1990 expenditure growth rate between adopters and nonadopters offset the difference-in-difference "levels" effect; in total, malpractice reforms always result in a decline in cost growth of at least 10 percent.

The remaining columns of Table 4 describe the corresponding DD estimates of reform effects on AMI outcomes. Mortality rates declined but readmission rates with cardiac complications increased during this time period, confirming the results of Table 1. Outcome trends were very similar in reform and nonreform states; the cumulative difference in mortality and cardiac-complication trends was around 0.1 percentage points. These small estimated 
mortality differences are not only insignificantly different from zero; they are estimated rather precisely as well. For example, the upper 95 percent confidence limit for the effect of direct reforms on one-year mortality trends between 1984 and 1990 is 0.65 percentage points. Coupled with the estimated expenditure effect, the expenditure/benefit ratio for a higher-pressure liability regime is over $\$ 500,000$ per additional one-year AMI survivor in 1991 dollars; even a ratio based on the upper-bound mortality estimate translates into hospital expenditures of over $\$ 100,000$ per additional AMI survivor to one year. ${ }^{10}$ The estimates in the corresponding regioneffect models are very similar. Indirect reforms were also associated with estimated mortality effects that were very close to zero. Results for outcomes related to quality of life -- that is, rehospitalizations with either recurrent AMI or heart failure -- also showed no consequential effects of reforms. In this case, the point estimates (upper bound of the 95 percent confidence interval) for the estimated effect of direct reforms were $-0.18(0.22)$ percentage points for AMI recurrence and $-0.07(0.29)$ percentage points for the occurrence of heart failure. Again, compared to the estimated expenditure effects, these differences are not substantial.

Table 5 presents estimated effects of malpractice reforms on IHD expenditures and outcomes, with results qualitatively similar to those just described for AMI. IHD expenditures also grew rapidly between 1984 and 1990 . Direct reforms led to somewhat larger expenditure reductions for IHD (9.0 percent) and indirect reforms were again associated with relatively smaller increases in expenditures ( 3.4 percent). The effects of reforms on IHD outcomes are again very small: the effect of direct reforms on mortality rates was an average difference of -0.19 percentage points (95 percent upper confidence limit of 0.11 ), and the effects on subsequent occurrence of AMI or heart failure hospitalizations were no larger. ${ }^{11}$ Estimates from 
the models with region effects were very similar. Thus, direct liability reforms appear to have a relatively larger effect on IHD expenditures, without substantial consequences for health outcomes.

As we noted in Section III, the simple average effects of liability reforms estimated in the DD specifications of Tables 4 and 5 may not capture the dynamic effects of reforms. Table 6 presents results from model specifications that estimate reform effects less restrictively. In these specifications, we use our seven-year panel to estimate short-term and long-term effects of direct and indirect reforms on expenditures and outcomes, to determine whether the "shift" effect implied by the DD specification is adequate. The models retain our state and time fixed effects. ${ }^{12}$ We find the same general patterns as in the simple DD models, but somewhat larger effects of malpractice reforms three to five years after adoption compared to the short-term effects. In particular, Table 6 shows that direct reforms lead to short-term reductions in AMI expenditures of approximately 4.0 percent within two years of adoption, and that the reduction grows to approximately 5.8 percent three to five years after adoption. This specification also shows that the positive association between indirect reforms and expenditures noted in Table 4 is a short-term phenomenon; the long-term effect on expenditures is approximately zero. ${ }^{13}$

As in Table 4, both direct and indirect reforms have trivial effects on mortality and readmissions with complications, both soon and later after adoption. For example, the average difference in mortality trends between direct-reform and nonreform states is -0.22 percentage points (not significant) within two years of adoption, with a 95 percent upper confidence limit of 0.4 percentage points. At three to five years, the estimated effect is 0.12 percentage points (not significant) with a 95 percent upper confidence limit of 0.76 percentage points. These point 
estimates translate into very high expenditures per reduction in adverse AMI outcomes.

The results for the corresponding model of IHD effects over time are presented in the right half of Table 6. Direct reforms are associated with a 7.1 percent reduction in expenditures by two years after adoption (standard error 0.5 ) and an 8.9 percent reduction by five years after (standard error 0.5$){ }^{14}$ In contrast, mortality trends for states with direct reforms do not differ significantly by two years (point estimate of -0.15 percentage points, 95 percent upper confidence limit 0.19 ) or five years after adoption (point estimate -0.11 percentage points, 95 percent upper confidence limit $\mathbf{0 . 2 3}$ ). Direct reforms also have no significant or substantial effects on cardiac complications, either immediately or later. Indirect reforms are again associated with small positive effects on expenditure growth (3.1 percent within two years), but these effects decline over time to a relatively trivial level (1.4 percent at three to five years). Indirect reforms are also associated with slightly lower mortality rates and slightly higher rates of cardiac complications, but the size of these effects are very small (e.g., the upper limit of the 95 percent confidence interval around the estimated effect of indirect reforms three to five years after adoption is 0.47 percentage points for $\mathrm{AMI}$ recurrence and 0.30 percentage points for heart failure occurrence). Thus, the pattern of reform effects for IHD is again qualitatively similar to that for AMI, with direct reforms having a somewhat larger effect on expenditures.

Taken together, the estimates in Tables 4 through 6 consistently show that the adoption of direct malpractice reforms between 1984 and 1990 led to substantial relative reductions in hospital expenditures during this period -- accumulating to a reduction of more than five percent for AMI and nine percent for IHD by five years after reform adoption -- and that these expenditure effects were not associated with any consequential effects on mortality or on the 
rates of significant cardiac complications.

We estimated a variety of other models to explore the robustness of our principal results. We tested the sensitivity of our results to alternative assumptions about the excludability of state/time interactions. One set of tests reestimated the models with random state/time effects, to determine whether correlated outcomes at the level of state/time interactions might affect our conclusions. Our estimated effects of reforms did not differ substantially or significantly with these methods. Using the model presented in Tables 4 and 5, the estimated difference-indifference effect of direct reform on expenditures for AMI patients, controlling for random state/time effects, is -4.9 percent (standard error 2.1); for indirect reform, the estimated effect is -0.6 percent (standard error 2.0). The estimated DD effect of direct reform on mortality for AMI patients, controlling for random state/time effects, is 0.15 percentage points (standard error 0.32 ); for indirect reform, the estimated effect is -0.19 percentage points (standard error 0.32 ). Similar results obtained for IHD patients: direct reform showed a negative and statistically significant effect on expenditures with an insubstantial and precisely estimated effect on mortality, and indirect reform showed no substantial effect on either expenditures or mortality. Estimated differential 1984-1990 expenditure growth rates between early-adopters and nonadopters were insignificant in the random effects specification. For AMI patients, the differential growth rate for early adopters of direct reforms is 0.61 percent (standard error 3.1 ); for early adopters of indirect reforms, the differential growth rate is 0.61 percent (standard error 2.3). For IHD patients, the differential growth rate for early adopters of direct reforms is -1.9 percent (standard error 3.0); for early adopters of indirect reforms, the differential growth rate is -3.2 percent (standard error 2.2). Another related diagnostic involved estimating the models 
with Huber-White [1980] corrections for state/time grouped errors instead of corrections for zipcode/time grouped errors. Standard errors corrected for state/time grouping were greater than those corrected for zip-code/time grouping but less than those obtained under the random effects specification.

Although they did have a statistically significant influence on expenditures in some models, the broad set of political and regulatory environment controls that we used did not change our results substantially. Using the models presented in Tables 4 and 5 but excluding controls for the regulatory and legal environment, the estimated DD effect of direct reforms on expenditures for AMI patients is -9.1 percent (standard error 0.44); for indirect reforms, the estimated DD effect is 3.3 percent (standard error 0.40 ). In addition, the difference in 19841990 growth rates between early-reforming and nonreforming states changes sign from positive to negative for states enacting direct reforms before 1985 (3.1 percent with legal environment controls (Table 4), -3.1 percent without them); the difference in growth rates for states enacting indirect reforms before 1985 remains about the same ( 2.76 percent with legal environment controls (Table 4), 3.5 percent without them). These two specification checks, taken together, underscore the points made by Tables 4 and 5 . Direct reforms reduce expenditure growth without increasing mortality; indirect reforms have no substantial effect on either expenditures or mortality; and differential 1984-1990 expenditure growth rates for early-adopting states are not robust estimates of the long-term impact of reforms.

Finally, we reestimated the models in Tables 4 and 5 including controls for statute-oflimitations reforms. Statute-of-limitation reforms have a very small positive effect on expenditures and no effect on mortality, which is consistent with their classification as an 
indirect reform. Using the models presented in Tables 4 and 5, statute-of-limitations reforms are associated with a 0.96 percent increase in expenditures for AMI patients (standard error 0.46), and a 0.003 percentage point increase in mortality (standard error 0.28 ). Inclusion of statute-oflimitation reforms did not substantially alter the estimated DD effect of either direct or indirect reforms: for AMI patients, the estimated effect of direct reforms went from -5.3 percent (Table 4) to -5.5 percent, and the estimated effect of indirect reforms remained constant at 1.8 percent (Table 4).

To explore the sources of our estimated reform effects more completely, we estimated additional specifications that analyzed effects on use of intensive cardiac procedures such as cardiac catheterization, that used alternative specifications of time-since-adoption and calendaryear effects, and that estimated the effects of each type of tort reform separately (see Table 2A). These specifications produced results consistent with the simpler specifications reported here for both AMI and IHD. Specifically, reforms with a determinate, negative direct impact on liability led to substantially slower expenditure growth, somewhat less growth in the use of intensive procedures (but smaller effects than would explain the expenditure differences, suggesting less intensive treatments were also affected), and no consequential effects on mortality.

\section{Conclusion}

We have developed evidence on the existence and magnitude of "defensive" medical practices by studying the consequences of reforms limiting legal liability on health care expenditures and outcomes for heart disease in the elderly. These results provide a critical extension to the existing empirical literature on the effects of malpractice reforms. Previous 
studies have found significant effects of direct reforms on the frequency of and payments to malpractice claims. Because the actual costs of malpractice litigation comprise a very small portion of total health care expenditures, however, these litigation effects have only a limited impact on health care expenditure growth. To provide a more complete assessment of malpractice reforms, we have studied their consequences for actual health care expenditures and health outcomes. Our study is the first to use exogenous variation in tort laws not related to potential idiosyncrasies of providers or small geographic areas to assess the behavioral effects of malpractice pressure. Thus, our analysis fills a crucial empirical gap in evaluating the U.S. malpractice liability system, because the effects of malpractice law on physician behavior are both a principal justification for current liability rules and potentially important for understanding medical expenditure growth.

Our analysis indicates that reforms that directly limit liability -- caps on damage awards, abolition of punitive damages, abolition of mandatory prejudgment interest, and collateralsource rule reforms -- reduce hospital expenditures by 5 to 9 percent within three to five years of adoption, with the full effects of reforms requiring several years to appear. The effects appear to be somewhat smaller for actual heart attacks than for a relatively less severe form of heart disease (IHD), for which more patients may have "marginal" indications for treatment. In contrast, reforms that limit liability only indirectly -- caps on contingency fees, mandatory periodic payments, joint-and-several liability reform, and patient compensation funds -- are not associated with substantial effects on either expenditures or outcomes, at least by several years after adoption. Neither type of reforms led to any consequential differences in mortality or the occurrence of serious complications. As we described previously, the estimated 
expenditure/benefit ratio associated with direct reforms is over $\$ 500,000$ per additional one-year survivor, with comparable ratios for recurrent AMIs and heart failure. Even the 95-percent confidence bounds for outcome effects are generally under one percentage point, translating into over $\$ 100,000$ per additional one-year survivor. While it is possible that malpractice reforms have had effects on other outcomes valued by patients, this possibility must be weighed against the absence of any substantial effects on mortality or the principal cardiac complications that are correlated with quality of life. Thus, the results indicate that liability rules that are more generous in terms of award limits are a very costly approach to improving health care outcomes. Approximately 40 percent of patients with cardiac disease were affected by direct reforms between 1984 and 1990. Based on simulations using our effect estimates, we conclude that if reforms directly limiting malpractice liability had been applied throughout the United States during this period, expenditures on cardiac disease would have been around $\$ 450$ million per year lower for each of the first two years after adoption and close to $\$ 600$ million per year lower for each of years three through five after adoption, compared with nonadoption of direct reforms.

While our panel is relatively lengthy for a DD study, it is not long enough to allow us to reach equally certain conclusions about the long-term effects of malpractice reforms on medical expenditure growth and trends in health outcomes. Plausible static effects of virtually all policy factors cannot explain more than a fraction of expenditure growth in recent decades [Newhouse 1992], and we have also documented that outcome trends may be quite important. Whether policy changes such as malpractice reforms influence these long-term trends through effects on the environment of technological change in health care is a critical issue. Do reforms have 
implications for trends in expenditures and outcomes long after they are adopted, or do the trend effects diminish over time? Preliminary evidence on this question from early-adopted (pre1985, mostly pre-1980) reforms suggest that long-term expenditure growth is not slower in states that adopt direct reforms; on the other hand, subsequent growth does not appear to offset the expenditure reductions that occur in the years following adoption. Moreover, we found no evidence that direct reforms adopted from 1985-1990 had smaller effects in states that had also adopted direct reforms earlier, suggesting that dynamic malpractice policies may produce more favorable long-term expenditure/benefit trends. In any event, our conclusions about long-term effects are speculative at this point, given the absence of baseline data on expenditures and outcome trends in reform states. Follow up evaluations of longer-term effects of malpractice reforms should be possible within a few years, and might help confirm whether liability reforms have any truly lasting consequences for expenditure growth or trends in health outcomes.

Hospital expenditures on treating elderly heart disease patients are substantial -- over \$8 billion per year in 1991 -- but they comprise only a fraction of total expenditures on health care. If our results are generalizable to medical expenditures outside the hospital, to other illnesses, and to younger patients, then direct reforms could lead to expenditure reductions of well over $\$ 50$ billion per year without serious adverse consequences for health outcomes. We hope to address the generalizability of our results more extensively in future research. More detailed studies using both malpractice claims information and patient expenditure and outcome information, linking the analysis of the two policy justifications for a malpractice liability system, should be particularly informative. Such studies could provide more direct evidence on how liability rules translate into effects on particular kinds of physician decisions with 
implications for medical expenditures but not outcomes. Thus, they may provide more specific guidance on which specific liability reforms -- including "nontraditional" reforms such as nofault insurance and mandatory administrative reviews -- will have the greatest impact on defensive practices without substantial consequences for health outcomes.

Our evidence suggests that doctors do practice defensive medicine, and that reforms that directly limit provider liability reduce defensive practices and thereby improve efficiency in the U.S. health care system. Given the limited relationship between malpractice claims and medical injuries documented in previous research, perhaps our findings that less malpractice liability does not have significant adverse consequences for patient outcomes but does affect expenditures are not surprising. To our knowledge, however, this is the first direct empirical quantification of the costs of defensive medicine. 


\begin{tabular}{|c|c|c|c|}
\hline \multicolumn{4}{|c|}{ AMI Population } \\
\hline & 1984 & 1987 & 1990 \\
\hline 1-Year Mortality & 39.9 & 38.8 & 35.4 \\
\hline 1-Year AMI Re-admit & 10.9 & 11.4 & 14.6 \\
\hline $\begin{array}{c}\text { 1-Year Heart Failure } \\
\text { Re-admit }\end{array}$ & 9.6 & 10.1 & 11.0 \\
\hline $\begin{array}{l}\text { 1-Year Total Hospital } \\
\text { Expenditures }\end{array}$ & $\$ 10,881$ & $\$ 11,996$ & $\$ 13,140$ \\
\hline $\begin{array}{c}\text { Mean Age } \\
\text { (Standard Deviation) }\end{array}$ & $\begin{array}{l}75.6 \\
(7.0)\end{array}$ & $\begin{array}{l}75.9 \\
(7.2)\end{array}$ & $\begin{array}{l}76.1 \\
(7.3)\end{array}$ \\
\hline Female & 48.5 & 49.6 & 49.6 \\
\hline Black & 5.1 & 5.4 & 5.5 \\
\hline Rural & 29.4 & 30.3 & 30.3 \\
\hline Sample Size & 232,768 & 227,360 & 220,550 \\
\hline \multicolumn{4}{|c|}{ IHD Population } \\
\hline & 1984 & 1987 & 1990 \\
\hline 1-Year Mortality & 13.5 & 11.6 & 10.6 \\
\hline 1-Year AMI Re-admit & 5.5 & 4.7 & 4.3 \\
\hline $\begin{array}{c}\text { 1-Year Heart Failure } \\
\text { Re-admit }\end{array}$ & 7.8 & 6.9 & 7.7 \\
\hline $\begin{array}{l}\text { 1-Year Total Hospital } \\
\text { Expenditures }\end{array}$ & $\$ 10,638$ & $\$ 11,187$ & $\$ 12,515$ \\
\hline $\begin{array}{c}\text { Mean Age } \\
\text { (Standard Deviation) }\end{array}$ & $\begin{array}{l}74.6 \\
(6.9)\end{array}$ & $\begin{array}{l}74.3 \\
(6.8)\end{array}$ & $\begin{array}{l}74.3 \\
(6.8)\end{array}$ \\
\hline Female & 55.2 & 53.4 & 51.4 \\
\hline Black & 5.7 & 5.7 & 5.8 \\
\hline Rural & 30.6 & 30.4 & 29.7 \\
\hline Sample Size & 356,717 & 372,871 & 381,222 \\
\hline
\end{tabular}

Notes: Hospital Expenditures in 1991 Dollars. Outcome measures and demographic characteristics except age in percentage points. 
TABLE IIA: LEGAL REFORMS USED IN ANALYSIS

\begin{tabular}{|c|c|c|}
\hline Reform & Description of Reform & Predicted Impact on Liability \\
\hline $\begin{array}{l}\text { Caps on damage } \\
\text { awards }\end{array}$ & $\begin{array}{l}\text { Either noneconomic (pain and suffering) or total damages payable are } \\
\text { capped at a statutorily-specified dollar amount }\end{array}$ & Direct \\
\hline $\begin{array}{l}\text { Abolition of punitive } \\
\text { damages }\end{array}$ & $\begin{array}{l}\text { Medical malpractice defendants are not liable for punitive damages } \\
\text { under any circumstances }\end{array}$ & Direct \\
\hline $\begin{array}{l}\text { No mandatory } \\
\text { prejudgment interest }\end{array}$ & $\begin{array}{l}\text { Interest on either noneconomic or total damages accruing from either } \\
\text { the date of the injury or the date of filing of the lawsuit is not } \\
\text { mandatory }\end{array}$ & Direct \\
\hline $\begin{array}{l}\text { Collateral-source rule } \\
\text { reform }\end{array}$ & $\begin{array}{l}\text { Total damages payable in a malpractice tort are statutorily reduced by } \\
\text { all or part of the dollar value of collateral source payments to the } \\
\text { plaintiff }\end{array}$ & Direct \\
\hline $\begin{array}{l}\text { Caps on contingency } \\
\text { fees }\end{array}$ & $\begin{array}{l}\text { The proportion of an award that a plaintiff can contractually agree to } \\
\text { pay a contingency-fee attorney is capped at a statutorily-specified } \\
\text { level }\end{array}$ & Indirect \\
\hline $\begin{array}{l}\text { Mandatory periodic } \\
\text { payments }\end{array}$ & $\begin{array}{l}\text { Part or all of damages must be disbursed in the form of an annuity } \\
\text { that pays out over time }\end{array}$ & Indirect \\
\hline $\begin{array}{l}\text { Joint-and-several } \\
\text { liability reform }\end{array}$ & $\begin{array}{l}\text { Joint and several liability is abolished for noneconomic or total } \\
\text { damages, either for all claims or for claims in which defendants did } \\
\text { not act in concert }\end{array}$ & Indirect \\
\hline $\begin{array}{l}\text { Patient compensation } \\
\text { fund }\end{array}$ & $\begin{array}{l}\text { Doctors receive government-administered excess malpractice liability } \\
\text { insurance, generally financed through a tax on malpractice insurance } \\
\text { premiums }\end{array}$ & Indirect \\
\hline
\end{tabular}


Table IIB: Chronology of Legal Reforms*

\begin{tabular}{|c|c|c|c|c|c|}
\hline State & \multicolumn{2}{|l|}{ Year Effective } & State & \multicolumn{2}{|l|}{ Year Effective } \\
\hline Alabama & 1987 & 1987 & Montana & 1987 & \\
\hline Arizona & & 1988 & Nevada & & \\
\hline Arkansas & & & New Hampshire & 1986 & \\
\hline California & 1975 & 1975,1986 & New Jersey & 1987 & 1972,1976 \\
\hline Connecticut & 1985 & 1986 & New York & 1967,1984 & 1970,1985 \\
\hline Delaware & & 1976 & North Carolina & & \\
\hline Florida & 1976,1986 & 1980,1985 & North Dakota & 1987 & 1987 \\
\hline Georgia & & & Ohio & 1975 & 1988 \\
\hline Hawaii & 1986 & & Oklahoma & & 1953,1978 \\
\hline Idaho & 1987,1990 & 1986,1987 & Oregon & 1975,1987 & $1975^{* *}, 1987$ \\
\hline Kansas & 1986,1988 & 1974,1976 & South Dakota & 1976 & 1988 \\
\hline Kentucky & & & Tennessee & 1975 & 1975 \\
\hline Louisiana & $1975, * * *$ & 1975,1984 & Texas & 1977 & \\
\hline Maine & 1989 & 1985,1988 & Utah & 1985,1986 & 1985,1986 \\
\hline Maryland & 1986 & & Vermont & & 1970 \\
\hline Massachusetts & $1986, * * *$ & 1986 & Virginia & 1974 & \\
\hline Michigan & 1986 & 1981 & Washington & $* * *$ & 1986 \\
\hline Minnesota & 1986 & & West Virginia & 1986 & \\
\hline Mississippi & & & Wisconsin & 1986 & 1975,1986 \\
\hline Missouri & 1986 & 1986 & Wyoming & & 1986,1987 \\
\hline
\end{tabular}


Table III: Hospital Expenditures and Mortality Outcomes in States With and Without Direct Reforms, AMI and IHD Patients, 1984-1990

\begin{tabular}{|c|c|c|c|c|c|c|c|c|c|c|}
\hline & \multicolumn{5}{|c|}{ 1-Year Total Hospital Expenditures } & \multicolumn{5}{|c|}{ 1-Year Mortality } \\
\hline & 1984 & 1987 & 1990 & $\begin{array}{l}\text { 1984-87 } \\
\text { \%Change }\end{array}$ & $\begin{array}{l}1984-90 \\
\text { \%Change }\end{array}$ & 1984 & 1987 & 1990 & $\begin{array}{l}1984-87 \\
\text { Change }\end{array}$ & $\begin{array}{l}\text { 1984-90 } \\
\text { Change }\end{array}$ \\
\hline \multicolumn{11}{|c|}{ AMI } \\
\hline States without Direct Reforms & $\$ 10,194$ & $\$ 11,810$ & $\$ 12,618$ & $15.9 \%$ & $23.8 \%$ & $40.2 \%$ & $39.1 \%$ & $35.7 \%$ & $-1.1 \%$ & $-4.5 \%$ \\
\hline $\begin{array}{l}\text { States with Direct Reforms in } \\
\text { Effect Before } 1985\end{array}$ & $\$ 10,513$ & $\$ 11,722$ & $\$ 13,022$ & $11.5 \%$ & $23.9 \%$ & $40.1 \%$ & $39.0 \%$ & $35.4 \%$ & $-1.1 \%$ & $-4.7 \%$ \\
\hline $\begin{array}{l}\text { States Enacting Direct Reforms } \\
\text { Effective Between } 1985 \text { and } 1987\end{array}$ & $\$ 11,304$ & $\$ 12,595$ & $\$ 13,186$ & $11.4 \%$ & $16.6 \%$ & $39.5 \%$ & $38.6 \%$ & $35.3 \%$ & $-0.9 \%$ & $-4.2 \%$ \\
\hline $\begin{array}{l}\text { States Enacting Direct Reforms } \\
\text { Effective Between } 1988 \text { and } 1990\end{array}$ & $\$ 8,960$ & $\$ 9,865$ & $\$ 10,925$ & $10.1 \%$ & $21.9 \%$ & $41.9 \%$ & $39.2 \%$ & $35.7 \%$ & $-2.7 \%$ & $-6.2 \%$ \\
\hline \multicolumn{11}{|c|}{ IHD } \\
\hline States without Direct Reforms & $\$ 9,439$ & $\$ 10,859$ & $\$ 12,083$ & $15.0 \%$ & $28.0 \%$ & $14.1 \%$ & $12.0 \%$ & $11.0 \%$ & $-2.1 \%$ & $-3.1 \%$ \\
\hline $\begin{array}{l}\text { States with Direct Reforms in } \\
\text { Effect Before } 1985\end{array}$ & $\$ 10,331$ & $\$ 11,064$ & $\$ 12,505$ & $7.1 \%$ & $21.0 \%$ & $13.5 \%$ & $11.7 \%$ & $10.7 \%$ & $-1.8 \%$ & $-2.8 \%$ \\
\hline $\begin{array}{l}\text { States Enacting Direct Reforms } \\
\text { Effective Between } 1985 \text { and } 1987\end{array}$ & $\$ 10,527$ & $\$ 11,315$ & $\$ 12,300$ & $7.5 \%$ & $16.8 \%$ & $13.8 \%$ & $11.6 \%$ & $10.5 \%$ & $-2.2 \%$ & $-3.3 \%$ \\
\hline $\begin{array}{l}\text { States Enacting Direct Reforms } \\
\text { Effective Between } 1988 \text { and } 1990\end{array}$ & $\$ 9,241$ & $\$ 9,623$ & $\$ 11,421$ & $4.1 \%$ & $23.6 \%$ & $14.1 \%$ & $12.3 \%$ & $11.5 \%$ & $-1.8 \%$ & $-2.6 \%$ \\
\hline
\end{tabular}

Note: Hospital Expenditures in 1991 Dollars. 
Table IV: Effects of Tort Reforms on Expenditures and Outcomes of Acute Myocardial Infarction, Difference-in-Difference Specification

State- and Time-Fixed Effects

Variable
1-Year Hospital 1-Year

Mortality
Region- and Time-Fixed Effects

1-Year AMI 1-Year HF

Readmit
1-Year Hospital

Expenditures
1-Year

Mortality
1-Year AMI 1-Year HF

Readmit Readmit

Difference-in-Difference Effects of Reforms

Direct Reforms

$\begin{array}{ll}-5.30 & 0.07\end{array}$

$0.07-0.18$

-0.18
$(0.20)$

$-0.07$

$-6.71$

(0.46)

0.05

(0.28)

$-0.31$

(0.19)

$-0.14$

Indirect Reforms

$$
\begin{aligned}
& 1.81 \\
& (0.46)
\end{aligned}
$$

$-0.13$

$-0.04$

$-0.02$

3.37

(0.43)

0.10

(0.26)

$-0.09$

(0.18)

0.18)

$(0.18)$

(0.43)

\subsection{9}

(0.29)

22.64

(0.76)

$-5.51$

(0.44)

4.78

(0.31)

1.10

21.01
$(0.70)$

(0.46)

(0.32)

0.43

(0.30)

1.24

(0.73)

0.17

$-1.25$

(0.31)

0.25

(0.77)

(0.47)

(0.32)

$-0.28$

(0.21)

(0.30)

(0.19)

4.88

(0.49)

(0.44)

(0.28)

(0.50)

Differential 1984 Level. States with pre-1985 Reforms

Direct Reforms

4.97

$-0.45$

0.56

(0.30)

(0.21)

(0.19)

$\begin{array}{llll}4.97 & -0.89 & -0.08 & 0.21 \\ (0.57) & (0.34) & (0.23) & (0.21) \\ 1.75 & & & \\ (0.40) & -0.12 & 0.12 & 0.32 \\ & (0.24) & (0.17) & (0.15)\end{array}$

Indirect Reforms

(0.40)

(0.24)

(0.17)

Notes: Heteroskedasticity-consistent standard errors allowing for zip-code/time grouping in parentheses. Hospital Expenditures in 1991 dollars. Coefficients from 1 year hospital expenditures model *100 from regressions in logarithms; Coefficients from outcome models in percentage points. All models include controls for the regulatory/legal environment and patient demographic characteristics. Baseline growth rate calculated at the sample average level of regulatory/legal environment characteristics. 
Table V: Effects of Tort Reforms on Expenditures and Outcomes of Ischemic Heart Disease, Difference-in-Difference Specification

\begin{tabular}{|c|c|c|c|c|c|c|c|c|}
\hline \multirow[b]{2}{*}{ Variable } & \multicolumn{4}{|c|}{ State- and Time-Fixed Effects } & \multicolumn{4}{|c|}{ Region- and Time-Fixed Effects } \\
\hline & $\begin{array}{l}\text { 1-Year Hospital } \\
\text { Expenditures }\end{array}$ & $\begin{array}{l}\text { 1-Year } \\
\text { Mortality }\end{array}$ & $\begin{array}{l}\text { 1-Year AMI } \\
\text { Readmit }\end{array}$ & $\begin{array}{l}\text { 1-Year HF } \\
\text { Readmit }\end{array}$ & $\begin{array}{l}\text { 1-Year Hospital } \\
\text { Expenditures }\end{array}$ & $\begin{array}{l}\text { 1-Year } \\
\text { Mortality }\end{array}$ & $\begin{array}{l}\text { 1-Year AMI } \\
\text { Readmit }\end{array}$ & $\begin{array}{l}\text { 1-Year HF } \\
\text { Readmit }\end{array}$ \\
\hline \multicolumn{9}{|c|}{ Difference-in-Difference Effects of Reforms } \\
\hline Direct Reforms & $\begin{array}{l}-9.02 \\
(0.45)\end{array}$ & $\begin{array}{l}-0.19 \\
(0.15)\end{array}$ & $\begin{array}{l}-0.20 \\
(0.10)\end{array}$ & $\begin{array}{l}-0.12 \\
(0.12)\end{array}$ & $\begin{array}{l}-10.02 \\
(0.44)\end{array}$ & $\begin{array}{l}0.05 \\
(0.15)\end{array}$ & $\begin{array}{l}-0.19 \\
(0.10)\end{array}$ & $\begin{array}{l}-0.03 \\
(0.12)\end{array}$ \\
\hline Indirect Reforms & $\begin{array}{l}3.42 \\
(0.44)\end{array}$ & $\begin{array}{l}-0.42 \\
(0.15)\end{array}$ & $\begin{array}{l}0.24 \\
(0.10)\end{array}$ & $\begin{array}{l}0.19 \\
(0.12)\end{array}$ & $\begin{array}{l}4.06 \\
(0.40)\end{array}$ & $\begin{array}{l}-0.61 \\
(0.14)\end{array}$ & $\begin{array}{l}0.23 \\
(0.09)\end{array}$ & $\begin{array}{l}0.10 \\
(0.11)\end{array}$ \\
\hline \multicolumn{9}{|c|}{ Baseline 1984-1990 Growth Rate } \\
\hline & $\begin{array}{l}17.16 \\
(0.75)\end{array}$ & $\begin{array}{l}-2.78 \\
(0.25)\end{array}$ & $\begin{array}{l}-0.84 \\
(0.17)\end{array}$ & $\begin{array}{l}-0.92 \\
(0.21)\end{array}$ & $\begin{array}{l}18.56 \\
(0.73)\end{array}$ & $\begin{array}{l}-2.91 \\
(0.25)\end{array}$ & $\begin{array}{l}-0.98 \\
(0.16)\end{array}$ & $\begin{array}{l}-1.00 \\
(0.20)\end{array}$ \\
\hline \multicolumn{9}{|c|}{ Differential 1984-1990 Growth Rate. States with pre-1985 Reforms } \\
\hline Direct Reforms & $\begin{array}{l}-1.41 \\
(0.76)\end{array}$ & $\begin{array}{l}0.33 \\
(0.26)\end{array}$ & $\begin{array}{l}-0.39 \\
(0.17)\end{array}$ & $\begin{array}{l}0.56 \\
(0.21)\end{array}$ & $\begin{array}{l}-3.06 \\
(0.73)\end{array}$ & $\begin{array}{l}0.42 \\
(0.25)\end{array}$ & $\begin{array}{l}-0.21 \\
(0.16)\end{array}$ & $\begin{array}{l}0.61 \\
(0.20)\end{array}$ \\
\hline Indirect Reforms & $\begin{array}{l}-1.04 \\
(0.47)\end{array}$ & $\begin{array}{l}-0.32 \\
(0.16)\end{array}$ & $\begin{array}{l}0.11 \\
(0.11)\end{array}$ & $\begin{array}{l}-0.29 \\
(0.13)\end{array}$ & $\begin{array}{l}0.87 \\
(0.46)\end{array}$ & $\begin{array}{l}-0.31 \\
(0.16)\end{array}$ & $\begin{array}{l}0.01 \\
(0.11)\end{array}$ & $\begin{array}{l}-0.22 \\
(0.13)\end{array}$ \\
\hline \multicolumn{9}{|c|}{ Differential 1984 Level. States with pre-1985 Reforms } \\
\hline Direct Reforms & & & & & $\begin{array}{l}6.88 \\
(0.57)\end{array}$ & $\begin{array}{l}-0.66 \\
(0.19)\end{array}$ & $\begin{array}{l}-0.34 \\
(0.13)\end{array}$ & $\begin{array}{l}-0.61 \\
(0.15)\end{array}$ \\
\hline Indirect Reforms & & & & & $\begin{array}{l}2.71 \\
(0.38)\end{array}$ & $\begin{array}{l}-0.24 \\
(0.13)\end{array}$ & $\begin{array}{l}-0.19 \\
(0.09)\end{array}$ & $\begin{array}{l}-0.01 \\
(0.10)\end{array}$ \\
\hline
\end{tabular}

Notes: Heteroskedasticity-consistent standard errors allowing for zip-code/time grouping in parentheses. Hospital expenditures in 1991 dollars. Coefficients from 1year hospital expenditures model *100 from regressions in logarithms; Coefficients from outcome models in percentage points. All models include controls for the regulatory/legal environment and patient demographic characteristics. Baseline growth rate calculated at the sample average level of regulatory/legal environment characteristics. 
Table VI: Effects of Tort Reforms on Expenditures and Outcomes

Time-Since-Adoption Specification

\begin{tabular}{|c|c|c|c|c|c|c|c|c|}
\hline \multirow[b]{2}{*}{ Variable } & \multicolumn{4}{|c|}{ AMI, State- and Time-Fixed Effects } & \multicolumn{4}{|c|}{ IHD, State- and Time-Fixed Effects } \\
\hline & $\begin{array}{l}\text { 1-Year Hospital } \\
\text { Expenditures }\end{array}$ & $\begin{array}{l}\text { 1-Year } \\
\text { Mortality }\end{array}$ & $\begin{array}{l}\text { 1-Year AMI } \\
\text { Readmit }\end{array}$ & $\begin{array}{l}\text { 1-Year HF } \\
\text { Readmit }\end{array}$ & $\begin{array}{l}\text { 1-Year Hospital } \\
\text { Expenditures }\end{array}$ & $\begin{array}{l}\text { 1-Year } \\
\text { Mortality }\end{array}$ & $\begin{array}{l}\text { 1-Year AMI } \\
\text { Readmit }\end{array}$ & $\begin{array}{l}\text { 1-Year HF } \\
\text { Readmit }\end{array}$ \\
\hline \multicolumn{9}{|c|}{ Time-Since-Adoption Effects of Reforms } \\
\hline \multicolumn{9}{|c|}{ Adopted 1985 to 1990 , within the past 2 years or less } \\
\hline Direct Reforms & $\begin{array}{l}-3.95 \\
(0.52)\end{array}$ & $\begin{array}{l}-0.22 \\
(0.31)\end{array}$ & $\begin{array}{l}-0.25 \\
(0.22)\end{array}$ & $\begin{array}{l}-0.29 \\
(0.20)\end{array}$ & $\begin{array}{l}-7.08 \\
(0.49)\end{array}$ & $\begin{array}{l}-0.15 \\
(0.17)\end{array}$ & $\begin{array}{l}-0.17 \\
(0.11)\end{array}$ & $\begin{array}{l}-0.23 \\
(0.13)\end{array}$ \\
\hline Indirect Reforms & $\begin{array}{l}1.71 \\
(0.48)\end{array}$ & $\begin{array}{l}0.10 \\
(0.29)\end{array}$ & $\begin{array}{l}-0.32 \\
(0.20)\end{array}$ & $\begin{array}{l}-0.01 \\
(0.18)\end{array}$ & $\begin{array}{l}3.09 \\
(0.46)\end{array}$ & $\begin{array}{l}-0.24 \\
(0.15)\end{array}$ & $\begin{array}{l}0.21 \\
(0.10)\end{array}$ & $\begin{array}{l}0.31 \\
(0.12)\end{array}$ \\
\hline \multicolumn{9}{|c|}{ Adopted 1985 to 1990 , within the past 3 to 5 years } \\
\hline Direct Reforms & $\begin{array}{l}-5.80 \\
(0.53)\end{array}$ & $\begin{array}{l}0.12 \\
(0.32)\end{array}$ & $\begin{array}{l}0.19 \\
(0.22)\end{array}$ & $\begin{array}{l}0.03 \\
(0.21)\end{array}$ & $\begin{array}{l}-8.88 \\
(0.50)\end{array}$ & $\begin{array}{l}-0.11 \\
(0.17)\end{array}$ & $\begin{array}{l}-0.16 \\
(0.11)\end{array}$ & $\begin{array}{l}0.08 \\
(0.14)\end{array}$ \\
\hline Indirect Reforms & $\begin{array}{l}-0.14 \\
(0.58)\end{array}$ & $\begin{array}{l}-0.23 \\
(0.35)\end{array}$ & $\begin{array}{l}0.06 \\
(0.24)\end{array}$ & $\begin{array}{l}-0.12 \\
(0.23)\end{array}$ & $\begin{array}{l}1.43 \\
(0.55)\end{array}$ & $\begin{array}{l}-0.70 \\
(0.19)\end{array}$ & $\begin{array}{l}0.21 \\
(0.13)\end{array}$ & $\begin{array}{l}-0.00 \\
(0.15)\end{array}$ \\
\hline \multicolumn{9}{|c|}{ Baseline 1984-1990 Growth Rate } \\
\hline & $\begin{array}{l}21.54 \\
(0.72)\end{array}$ & $\begin{array}{l}-5.51 \\
(0.47)\end{array}$ & $\begin{array}{l}4.84 \\
(0.33)\end{array}$ & $\begin{array}{l}0.94 \\
(0.30)\end{array}$ & $\begin{array}{l}17.11 \\
(0.77)\end{array}$ & $\begin{array}{l}-2.91 \\
(0.27)\end{array}$ & $\begin{array}{l}-0.98 \\
(0.20)\end{array}$ & $\begin{array}{l}-1.00 \\
(0.20)\end{array}$ \\
\hline \multicolumn{9}{|c|}{ Differential 1984-1990 Growth Rate. States with pre-1985 Reforms } \\
\hline Direct Reforms & $\begin{array}{l}3.54 \\
(0.77)\end{array}$ & $\begin{array}{l}0.39 \\
(0.47)\end{array}$ & $\begin{array}{l}-1.56 \\
(0.32)\end{array}$ & $\begin{array}{l}0.47 \\
(0.30)\end{array}$ & $\begin{array}{l}-0.53 \\
(0.76)\end{array}$ & $\begin{array}{l}0.37 \\
(0.26)\end{array}$ & $\begin{array}{l}-0.35 \\
(0.17)\end{array}$ & $\begin{array}{l}0.67 \\
(0.21)\end{array}$ \\
\hline Indirect Reforms & $\begin{array}{l}3.20 \\
(0.51)\end{array}$ & $\begin{array}{l}-0.52 \\
(0.31)\end{array}$ & $\begin{array}{l}0.49 \\
(0.21)\end{array}$ & $\begin{array}{l}-0.25 \\
(0.20)\end{array}$ & $\begin{array}{l}-0.42 \\
(0.48)\end{array}$ & $\begin{array}{l}-0.24 \\
(0.16)\end{array}$ & $\begin{array}{l}0.13 \\
(0.11)\end{array}$ & $\begin{array}{l}-0.22 \\
(0.13)\end{array}$ \\
\hline
\end{tabular}

Notes: Heteroskedasticity-consistent standard errors allowing for zip-code/time grouping in parentheses. Hospital expenditures in 1991 dollars. Coefficients from 1 -year hospital expenditures model *100 from regressions in logarithms; Coefficients from outcome models in percentage points. All models include controls for the regulatory/legal environment and patient demographic characteristics. Baseline growth rate calculated at the sample average level of regulatory/legal environment characteristics. 


\section{References}

Barker, D.K., "The Effects of Tort Reform on Medical Malpractice Insurance Markets: An Empirical Analysis," Journal of Health Politics. Policy and Law XVII (1992): 143-161.

Baldwin, L.M., et al., "Defensive Medicine and Obstetrics," JAMA CCLXXIV (1995): 16061610 .

Bell, P.A., "Legislative Intrusions into the Common Law of Medical Malpractice: Thoughts About the Deterrent Effect of Tort Liability," Syracuse Law Review XXXV (1984): 939-993.

Campbell, T.J., D.P. Kessler, and G.B. Shepherd, "Liability Reforms' Causes and Economic Impacts," in The Mosaic of Economic Growth, Landau, R. et al. (ed.) (Stanford, CA: Stanford University Press, 1996).

Charles, S.C., C.E. Pyskoty, and A. Nelson, "Physicians on Trial - Self-Reported Reactions to Malpractice Trials," The Western Journal of Medicine CXLVIII (1988): 358-360.

Cooter, Robert D. and Ulen, Thomas S., "An Economic Case For Comparative Negligence," New York University Law Review LXI (1986): 1067-1110.

Craswell, Richard and Calfee, John, "Deterrence and Uncertain Legal Standards," Journal of Law. Economics, and Organization II (1986): 279-303.

Cutler, D.M. and McClellan, Mark, "What is Technological Change?" Harvard Mimeo (1995).

Danzon, P.M., "The Frequency and Severity of Medical Malpractice Claims," RAND R-2870ICJ/HCFA (1982).

Danzon, P.M., Medical Malpractice: Theory, Evidence, and Public Policy (Cambridge, MA: Harvard University Press, 1985).

Danzon, P.M., "New Evidence on the Frequency and Severity of Medical Malpractice Claims," RAND R-3410-ICJ (1986).

Farber, H.S. and White, M.J., "Medical Malpractice: An Empirical Examination of the Litigation Process," RAND Journal of Economics XXII (Summer 1991): 199217.

Harvard Medical Practice Study, Patients, Doctors, and Lawyers: Medical Injury Malpractice Litigation. and Patient Compensation in New York, a report of the Harvard Medical Practice Study to the state of New York (Cambridge, MA: The President and Fellows of Harvard College, 1990). 
Keeton, W.P., et al., Prosser and Keeton on Torts, 5th. ed., (St. Paul, MN: West Publishing Co., 1984).

Leveno, K.J., et al., "A Prospective Comparison of Selective and Universal Electronic Fetal Monitoring in 34,995 Pregnancies," The New England Journal of Medicine CCCXV (1986): 614-619.

Localio, A.R., et al.,"Relationship Between Malpractice Claims and Cesarean Delivery," IAMA CCLXIX (1993): 366-373.

Masters, S.J., et al., "Skull X-Ray Examinations After Head Trauma: Recommendations by a Multidisciplinary Panel and Validation Study," New England Journal of Medicine CCCXVI (1987): 84-91.

McClellan, Mark, "Why Do Hospital Costs Keep Rising? Hospital Reimbursement, Hospital Production and the Puzzles of Medicare's Prospective Payment System", Harvard Mimeo (1994).

McClellan, Mark, "Uncertainty, Health Care Technologies, and Health Care Costs," American Economic Review LXXXV (1995): 38-44.

McClellan, Mark and Newhouse, Joseph P., "The Marginal Benefits of Medical Treatment Intensity: Acute Myocardial Infarction in the Elderly," NBER Working Paper (1995a).

McClellan, Mark, and Newhouse, Joseph P., "The Marginal Costs and Benefits of Medical Technology: Acute Myocardial Infarction,” Joumal of Econometrics, forthcoming (1995b).

Moser, J. and R. Musaccio, "The Cost of Medical Professional Liability in the 1980s," Medical Practice Management (Summer 1991): 3-9.

National Center for Health Statistics, Health United States, (Washington, DC: U.S. Government Printing Office, 1994).

Newhouse, J.P., “Medical Care Costs: How Much Welfare Loss?” Lournal of Economic Perspectives VI (1992): 3-22.

Physician Insurers Association of America (PIAA), Data Sharing Reports (1993).

Priest, George L., "The Current Insurance Crisis and Modern Tort Law," Yale Law Journal XCVI (1987): 1521-1589.

Rabin, Robert L., "Some Reflections on the Process of Tort Reform, San Diego Law Review XXV (1988): 13-48. 
Reynolds, R.A., J.A. Rizzo, M.L. Gonzales, "The Cost of Medical Professional Liability," JAMA CCLVII (1987): 2776-2781.

Rock, S.M., "Malpractice Premiums and Primary Cesarian Section Rates in New York and Illinois," Public Health Reporter CVIII (1988): 459-468.

Shy, K.K., et al., "Effects of Electronic Fetal-Heart-Rate Monitoring, as Compared with Periodic Auscultation, on the Neurologic Development of Premature Infants," The New England Journal of Medicine CCCXXII (1990): 588-593.

Sloan, F.A., "Experience Rating: Does It Make Sense for Medical Malpractice Insurance?" American Economic Review LXXX (1990): 128-133.

Sloan, F.A., P.M. Mergenhagen, and R.R. Bovbjerg, "Effects of Tort Reforms on the Value of Closed Medical Malpractice Claims: A Microanalysis," Journal of Health Politics, Policy and Law XIV (1989): 663-689.

U.S. Congress, Office of Technology Assessment, Impact of Legal Reforms on Medical Malpractice Costs, OTA-BP-H-1 19, (Washington, DC: U.S. Government Printing Office, 1993).

U.S. Congress, Office of Technology Assessment, Defensive Medicine and Medical Malpractice, OTA-H-602, (Washington, DC: U.S. Government Printing Office, 1994).

Weiler, P.C., et al., A Measure of Malpractice: Medical Injury, Malpractice Litigation, and Patient Compensation (Cambridge, MA: Harvard University Press, 1993).

White, H., "A Heteroskedasticity-Consistent Covariance Matrix Estimator and a Direct Test for Heteroskedasticity," Econometrica XLVII (1980): 817-838.

Zuckerman, S., R.R. Bovbjerg, and F. Sloan, "Effects of Tort Reforms and Other Factors on Medical Malpractice Insurance Premiums," Inquiry XXVII (1990): 167-182. 


\section{Endnotes}

1. Reforms requiring collateral-source offset revoke the common-law default rule which states that the defendant must bear the full cost of the injury suffered by the plaintiff, even if the plaintiff were compensated for all or part of the cost by an independent or "collateral" source. Under the common-law default rule, defendants liable for medical malpractice always bear the cost of treating a patient for medical injuries resulting from the malpractice, even if the treatment were financed by the patient's own health insurance. Either the plaintiff enjoys double recovery (the plaintiff recovers from the defendant and his own health insurance for medical expenses attributable to the injury) or the defendant reimburses the plaintiff's (subrogee) health insurer, depending on the plaintiff's insurance contract and state or federal law. However, some states have enacted reforms that specify that total damages payable in a malpractice tort are to be reduced by all or part of the value of collateral source payments.

2. Estimates of the impact of reforms on claim severity vary over time and across studies. Based on 1975-1978 data, Danzon [1982: 30] reports that states enacting caps on damages had 19 percent lower awards, and states enacting mandatory collateral source offsets had 50 percent lower awards. Based on 1975-1984 data, Danzon [1986: 26] reports that states enacting caps had 23 percent lower awards, and states enacting collateral source offsets had 11 to 18 percent lower awards. Based on 1975-1978 and 1984 data, Sloan, Mergenhagen, and Bovbjerg [1989] find that caps reduced awards by 38 to 39 percent, and collateral source offsets reduced awards by 21 percent.

3. Again, because all elderly patients with serious heart disease during the years of our study are included, this consideration applies only to extending the results to other patient populations. 4. Of course, if such state-time specific effects exist, there is no reason to expect that they would be normally distributed; normality assumptions in error structures generally have not performed 
well in models of health expenditures and outcomes. However, incorporating such random effects permits us to explore the robustness of our estimation methods to possible state-time specific shifts.

5. According to Danzon $[1982,1986]$, urbanization is a highly significant determinant both of claim payments to and the frequency of claims and of the enactment of tort reforms; we control for urbanization at the individual level as discussed below.

6. Although we did not include controls for the number of physicians per capita in the reported results because of concerns regarding the exogeneity of that variable, results conditional on physician density are virtually identical. We include both a current- and a one-year-lagged effect to account for the possibility that past political environments influence current law. 7. Data on lawyers per capita for 1980,1985 , and 1988 are from The Lawyer Statistical Report (Chicago, IL: The American Bar Foundation, 1985, 1991). Intervening years are calculated by linear interpolation. Data on state political environments are courtesy of Gary King.

8. Our data set is partially derived from Campbell, Kessler, and Shepherd [1996].

9. The baseline is defined as the "negligence rule" without any of the liability-reducing reforms studied here and with mandatory prejudgment interest.

10. That is, $(.053 * \$ 13,140) / .0065 \approx \$ 107,000$ using the $95 \%$ upper bound of the estimated mortality effect and $(.053 * \$ 13,140) / .0007 \approx \$ 1,000,000$ using the actual DD estimate. Both of these ratios are very large; the difference in absolute magnitude of the two estimates results from the denominator being very close to zero.

11. Because we were concerned that reforms might affect the rate of IHD hospitalization as well as outcomes among patients hospitalized, we estimated models analogous to the specifications reported using population hospitalization rates with IHD as the dependent variable. We found no significant or substantial effects of either direct or indirect reforms on IHD hospitalization 
rates.

12. Models with region effects only, analogous to the right half of Tables 4 and 5, again showed very similar effect estimates.

13. We also estimate separate time-trend effects for early-reform (pre-1984) states. This approach may permit the development of some evidence on "long-term" effects of reforms on intensity growth rates; as noted previously, we find no evidence for such effects. Of course, our lack of a pre-adoption baseline for the early-adopting states precludes DD identification and makes the long-term conclusion more speculative. A follow up study using more recent expenditure and outcome data would provide more convincing evidence on effects beyond five years.

14. In contrast to AMI, the slower rate of expenditure growth between 1984 and 1990 for earlyreform states (see Table 5) suggests that reforms may have longer-term effects on slowing IHD expenditure growth. 